\title{
Valence state partitioning of $V$ between pyroxene and melt for martian melt compositions $Y 980459$ and QUE 94201: The effect of pyroxene composition and crystal structure
}

J.J. Papike (jpapike@unm.edu), P.V. Burger ${ }^{1}$, A.S. Bell ${ }^{1}$, C.K. Shearer ${ }^{1}$, Loan Le $^{2}$, J. Jones ${ }^{3}$

Institute of Meteoritics, Department of Earth and Planetary Sciences, University of New Mexico, Albuquerque New Mexico 87131, ${ }^{2}$ ESCG, Houston, TX 77058, ${ }^{3}$ NASA/Johnson Space Center, Houston, TX 77058

Introduction. A spiked (with REE, V, Sc) martian basalt Y980459 composition was used to synthesize olivine, spinel, and pyroxene at $1200{ }^{\circ} \mathrm{C}$ at 5 oxygen fugacities: IW-1, IW, IW +1 , IW +2 , and QFM. The high spike levels for REE were used for two specific reasons. First, we wanted to be able to analyze REE by both electron microprobe and ion probe. Second, we wanted the most important "Others" components, (i.e., those outside the pyroxene quadrilateral such as $\mathrm{Al}, \mathrm{Cr}^{3+}, \mathrm{Fe}^{3+}, \mathrm{REE}^{3+}, \mathrm{V}^{3+}, \mathrm{V}^{4+}$, etc.) to be $\mathrm{REE}^{3+} \mathrm{Mg}$ $(\mathrm{Si}, \mathrm{Al})_{2} \mathrm{O}_{6}$. At the doped levels we used, the most important "Others" component is $\mathrm{REE}^{3+}$ in the M2 site coupled with $\mathrm{Al}$ in the tetrahedral site. The goal of this paper is to explain the significant increase in the value of $\mathrm{D}_{\mathrm{V}}^{\text {pyroxene/melt }}$ with increased Wo content of the pyroxene. We compare augite (Wo $\sim 33$ ), pigeonite (Wo $\sim 13$ ) and orthopyroxene (Wo $\sim 3.8$ ). We also show olivine for comparison. The crystal chemical factors which account for this remarkable increase of $\mathrm{D}_{\mathrm{V}}$ with Wo are twofold. First, with $\mathrm{Ca}$ in the $\mathrm{M} 2$ site (as in diopside, $\mathrm{CaMgSi}_{2} \mathrm{O}_{6}$ ) the site is large and 8-coordinated while $\mathrm{Mg}$ in the M2 site (as in enstatite, $\mathrm{Mg}_{2} \mathrm{Si}_{2} \mathrm{O}_{6}$ ) the site is smaller and 6coordinated. Second, tetrahedral Al in the pyroxene chains provides charge balance and makes the M2 site larger and more compliant for the introduction of REE.

Crystal chemical basis for different pyroxene Ds for $V$.

An early demonstration of the effect of the Wo content of pyroxene on Ds for REE was presented by McKay (1989). He showed that with increasing Wo content, the Ds for REE increased dramatically especially for the LREE. McKay states, "I interpret the partition coefficient variations in terms of the substitution of REE for $\mathrm{Ca}$ in the M2 site, and the principle is that the larger the difference between the size of the cation and the site which it will enter the more incompatible is the cation in that site. The M2 site can accommodate the HREE much more readily than the LREE..." Papike et al. (2005) laid the foundation for valence state partitioning of $\mathrm{Cr}, \mathrm{Fe}, \mathrm{Ti}$, and $\mathrm{V}$ among crystallographic sites in olivine, pyroxene, and spinel from planetary basalts. These authors showed the importance of cation size and also charge balance in substitution mechanisms. Figure 1 shows the importance of the effect of Wo content on the V Ds for pyroxene. Also shown is olivine for comparison. Olivine/melt is a better oxybarometer than $\mathrm{V}$ in pyroxene because olivine is not significantly affected by differences in $\mathrm{Ca}$ content. Karner et al. (2008) address the V substitution in the pyroxene structure. Coupled substitution is required to incorporate $\mathrm{V}^{3+}$ and $\mathrm{V}^{4+}$ into the pyroxene crystal structure because these cations are replacing divalent $\mathrm{Mg}$ and $\mathrm{Fe}$ in the $\mathrm{M} 1$ site (Papike et al. 2005), thus creating an excess charge of +1 or +2 . Crystal charge balance must be maintained and can be accomplished by simultaneously substituting 1) an $\mathrm{Al}$ cation(s) into the tetrahedral site for $\mathrm{Si}$ or 2) a Na cation(s) into the M2 site for Ca. Both of these substitutions create a charge deficiency of -1 (or -2), and thus neutralize the crystal charge. Therefore, an increase in $D_{v}$ from pigeonite to augite can be explained by the ease with which $\mathrm{Al}$ and $\mathrm{Na}$ can enter augite (compared to pigeonite) for the required charge-balancing coupled substitution. This explanation is supported by Fig. 2, which clearly shows that $\mathrm{Al}$ and $\mathrm{Na}$ increase from pigeonite to augite. We emphasize, however, that the $\mathrm{Ca}$ content, and structure of augite compared to pigeonite does not sufficiently explain $\mathrm{V}$ partitioning into pyroxene. Vanadium partitioning is dependent on both the structure of augite compared to pigeonite, (which allows more $\mathrm{Na}$ and $\mathrm{Al}$ to enter the structure) as well as on the coupled substitution. While the above discussion explains the difference of $D_{V}$ between augite and pigeonite, it does not explain the much lower $D_{V}$ for orthopyroxene. For that explanation refer to Papike (1987) who shows that there is a very important difference between augite (monoclinic space group $\mathrm{C} 2 / \mathrm{c}$ ) and pigeonite (monoclinic space group $\mathrm{P} 2{ }_{1} / \mathrm{c}$ ) verses orthopyroxene (orthorhombic space group Pbca). The difference involves the stacking of TOT layers (tetrahedraoctahedra-tetrahedra). In monoclinic pyroxenes, the stacking is ++++ (indicates the direction), a stacking pattern that produces the monoclinic offset. In orthopyroxene the stacking is +-+ , which produces an orthorhombic structure. The M2 site is located between the reversed TOT units and is highly constrained to 6-coordination and thus cannot contain significant $\mathrm{Ca}$ which requires 8-coordination. Therefore the charge balance exchange is vacancies for $\mathrm{V}^{3+}, \mathrm{V}^{4+}$, as in olivine [5]. This results in a different slope for $D_{V}$ for orthopyroxene [5]. Acknowledgements. We acknowledge support for this research from the NASA Cosmochemistry program to Charles Shearer and John Jones. 

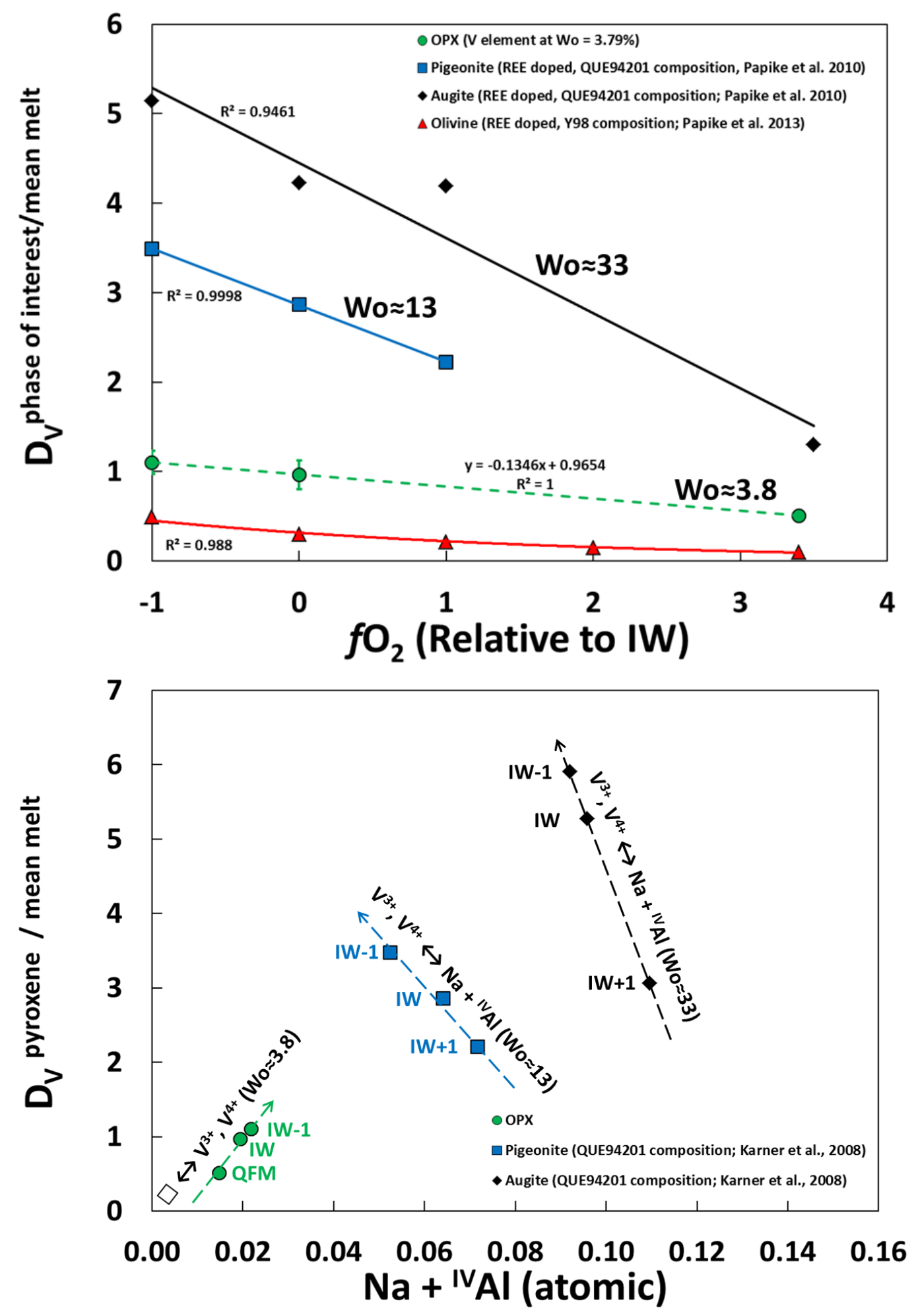

Figure 2. $D_{V}$ pyroxene/melt vs. other components $\left(\mathrm{Na}+{ }^{\mathrm{IV}} \mathrm{Al}\right.$, atomic). Note that the slopes for augite and pigeonite indicate a substitution mechanism, wherein $\mathbf{V}^{3+}, \mathbf{V}^{4+} \leftrightarrow$ $\mathrm{Na}+{ }^{\mathrm{IV}}$ Al. Opx has a different slope and is the same substitution mechanism as with olivine, $\mathbf{V}^{3+}, \mathbf{V}^{4+} \leftrightarrow \square$, where $\square=$ vacancies.

References. [1] McKay, G.A. (1989) RIM 21,45-77 [2] Papike et al. (2005) Am. Min. 90, 277-290. [3] Karner et al. (2008) MAPS 95. [4] Papike (1987) Reviews of Geophysics,25, 1483-1526. [5] Papike et al. (2013) Am. Min. in press. 